\title{
Simulation modelling: educational development roles for learning technologists
}

\author{
David Riley \\ Imperial College London \\ email:d.riley@imperial.ac.uk
}

Simulation modelling was in the mainstream of CAL development in the 1980s when the late David Squires introduced this author to the Dynamic Modelling System. Since those early days, it seems that simulation modelling has drifted into a learning technology backwater to become a member of Laurillard's underutilized, 'adaptive and productive' media. Referring to her Conversational Framework, Laurillard constructs a pedagogic case for modelling as a productive student activity but provides few references to current practice and available resources. This paper seeks to complement her account by highlighting the pioneering initiatives of the Computers in the Curriculum Project and more recent developments in systems modelling within geographic and business education. The latter include improvements to system dynamics modelling programs such as STELLA $A^{\circledR}$, the publication of introductory textbooks, and the emergence of online resources. The paper indicates several ways in which modelling activities may be approached and identifies some educational development roles for learning technologists. The paper concludes by advocating simulation modelling as an exemplary use of learning technologies - one that realizes their creative-transformative potential.

\section{Foreword}

I first encountered David Squires at Hertfordshire's Advisory Unit for Computer Based Education in 1981, little knowing that we were destined to share an office at Chelsea College and to work for the pioneering Computers in the Curriculum Project (CIC). On joining Chelsea's Educational Computing Unit in 1983, David soon introduced me to his work with Jon Ogborn on the Dynamic Modelling System and their combined influences are apparent still, both in my educational research and in this paper.

David was a pioneer at heart with a laid-back enthusiasm for innovative ideas and the educational opportunities afforded by microcomputers. During the $1980 \mathrm{~s}$, he managed and directed a variety of educational projects encompassing simulations, games, modelling 
programs, science microworlds and a collaborative environmental database - pretty much the full gamut of what Laurillard terms the adaptive and productive media. Despite the range of David's interests and the ambition of his software development projects, he brought to his work a characteristic good humour, never being overwhelmed by his increasing responsibilities as he progressed from being a co-director of CIC to become a lecturer and, eventually, a professor of King's College London.

David's success may be attributable to his easy-going manner and a combination of a dayto-day pragmatism with a long-term educational vision. This proved to be a potent mix and one that endeared him to many of his colleagues and friends. Today, we miss his personal and professional presence and can only wonder what he might have gone on to achieve. We look to a new generation of learning technologists for his natural successors.

\section{Time for change}

Educational games, simulations, microworlds and modelling programs were in the mainstream of 1980 s computer-assisted learning (CAL) when students were expected to engage and participate, to compete and collaborate, and to create and produce within their theoretical fields. Since then, the technologies have improved by leaps and bounds whilst the adaptive and productive media seemingly have drifted into an educational backwater. These media receive only passing mention in the ALT overview of learning technologies (Seale and Rius-Riu, 2001), and Laurillard (2002), suggests that they are underdeveloped and underutilized in higher education. It is as though the users of learning technologies have turned their backs on students as creators and producers, in favour of enhanced information delivery and ease of administration.

To correct this apparent mission drift, it is suggested that learning technologists raise staff awareness of simulation modelling with programs like STELLA (see Figure 1), that support both modelling activities by students and the development of educational simulations.

Figure 1: A STELLA ${ }^{\circledR}$ simulation control panel - assembled from drag and drop components, as is the underlying systems model ('Population and Resources' model provided with STELLA 7 by High Performance Systems')

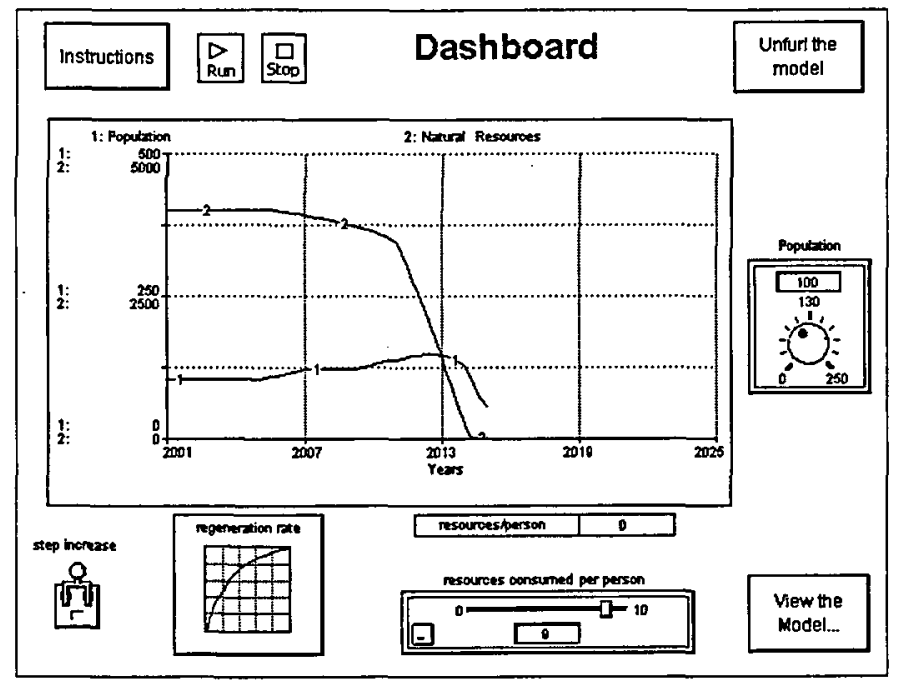


A pedagogic case for the productive media is made by Laurillard, who points to their unique potential for letting students create and produce their own mathematical and formal models of the world (Laurillard, 2002). Computer simulations and games allow students to interact with pre-defined dynamic models but only microworlds and modelling programs allow students readily to create such models for themselves. This paper seeks to illustrate this notion of students as the authors of models and seeks to complement Laurillard's account by highlighting:

- the 1980s modelling initiatives of David Squires and the Computers in the Curriculum Project;

- subsequent developments in the learning and teaching of systems modelling, with special reference to geographic and business education;

- educational development roles for learning technologists interested in promoting and supporting simulation modelling.

This quick dash through time, and the world of modelling, is inevitably partial and illustrative rather than comprehensive and definitive. The paper introduces just two models and modelling programs prior to a discussion of approaches to classroom modelling and educational development roles for learning technologists. An extensive list of references has been provided to compensate for this selectivity, and for the lack of case studies or of evaluations of classroom use. In the latter respect, modelling provides particular challenges. Modelling is a creative and relatively open-ended activity, there are no paperbased equivalents, the pedagogy of modelling is weakly developed across the curriculum, and modelling is still a comparatively rare educational activity. Indeed, one hopes that this paper will attract learning technologists to these unexplored pedagogic frontiers and to seek out covert instances of modelling within their own institutions.

\section{Modelling in the 1980s: a CIC perspective}

One cannot write about modelling in the UK in the 1980s without mention of David Squires. He spent much of the 1980s as a co-director of the Computers in the Curriculum Project where he was an international figure in the development of games, simulations, microworlds and modelling software for science curricula (Squires and McDougall, 1986; Watson, 1987). David championed the educational use of microworlds and modelling programs and, to take just one example, worked with Jon Ogborn to produce the Dynamic Modelling System (DMS), which is described below.

\section{Modelling with DMS}

DMS enabled students to create computer models without first having to learn calculus and a programming language such as FORTRAN (Lal, 1987; Riley, 1986; Wong, 1987). As with early spreadsheets, or predecessors such as MODL (Hartley and Lewis, 1984; Hartley, 1984), students could use DMS to explore the theories of their subject fields, whilst the computer performed the repetitive numerical calculations.

DMS was significant because it widened student, and teacher, access to simulation modelling as a learning activity. Providing access to a novel classroom activity was not sufficient however, and it was recognized that packs of illustrative models and guidance on their use would be needed. Hence, David directed the publication of sets of illustrative 
models for sixth-form and undergraduate Physics, Chemistry, Biology, Economics and Geography. An example of an elementary demographic model is shown in Figure 2. Such a model was intended to serve as a starting point for modelling activities in the life or social sciences where students were to investigate the growth of plant, insect, animal or human populations. The models were meant to be simple so that students could readily comprehend, criticize and improve upon them. Some illustrative sequences of progressively more complex models were included in the DMS packs to show how modelling activities might proceed through processes of elaboration and refinement.

Figure 2: An elementary demographic model as viewed in the four display pads of the Dynamic Modelling System: any two of the four pads could be displayed simultaneously on the low resolution screens of 8 -bit microcomputers

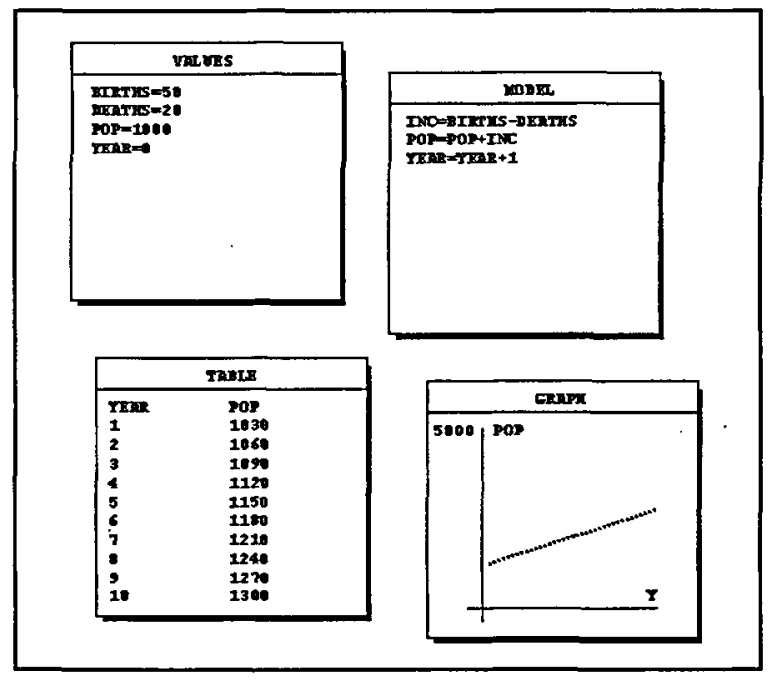

Figure 2 reproduces the display pads of DMS with a model of annual population growth resulting from constant numbers of births and deaths. DMS calculated the results from the initial values and the model's difference equations, with each iteration of the model standing for the passage of a short time interval. Models were expressed as mathematical 'difference equations' written in the BASIC programming language, thus a statement like: 'POP = POP + INC' was read as: 'LET the current size of the population BECOME EQUAL TO the previous size of the population PLUS the increase in population.'

Once students were familiar with DMS, they could adapt and extend the models. For example, the above model could be improved by introducing crude birth and death rates, in place of the fixed annual increments. The inclusion of immigration and emigration rates could add further dimensions to a model of, say, a period of industrial growth in Victorian Manchester or 1980s Hong Kong. Students could gather empirical data on critical rates of change, investigate their model's sensitivity to different rates of change, and relate their findings to known or anticipated trends in real-life populations.

Using learning technologies in this way was educationally attractive as students were engaged in researching, authoring and evaluating models. For instance, students using DMS might have to: 
- locate suitable numeric data, whilst coping with different units and systems of measurement;

- assess the relevance of available data and/or make reasonable estimates of values;

- establish empirical or theoretical relationships between variables;

- express these relationships logically/mathematically;

- make sense of tables and graphs of results;

- debug or refine their models - until the results were satisfactory;

- use the model to solve a problem or to arrive at a forecast.

Students typically worked in groups, and so modelling served as a stimulus for valuable communicative and collaborative activities. Furthermore, many hours of productive learning could be stimulated by a well-designed activity whilst the development of starter models and model fragments was a relatively quick task for teachers. If time was pressing, teachers could 'model' or demonstrate the process of modelling and engage students in whole-class discussions as a model was created, tested and applied to a problem.

\section{Modelling with STELLA}

The system dynamics modelling program STELLA ${ }^{\circledR}$ was launched on the Apple Macintosh in 1985 and it immediately impressed David Squires and fellow CIC staff. STELLA performed a similar function to DMS but possessed a graphical interface based on a 'visual plumbing metaphor', as shown in Figure 3. The cloud symbols indicate the system boundary and serve as infinite sources or sinks of the 'fluid' flowing through the system. The diagram is animated when the model is run, showing fluid levels rising and falling in the tank, whilst pointers on the dials of taps and the 'Limit_to_growth_fraction' converter move back and forth in response to changing flows and numeric values. Hence, the acronym STELLA: Structural Thinking Experiential Learning Laboratory with Animation.

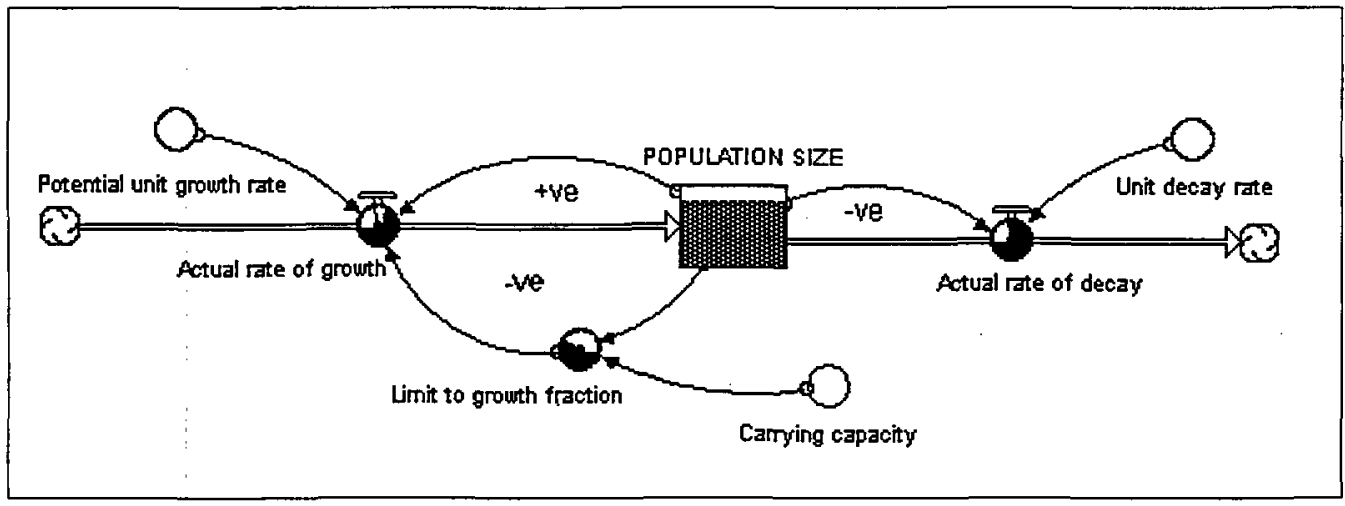

Figure 3: STELLA diagram of a simple Limits to Growth' model: with annotations identifying the positive (+ve) and negative (-ve) feedback loops 


\section{System dynamics stories}

System dynamics models show how system behaviour is determined by system structure conceptualized as accumulations, rates of change, delays and closed loops exhibiting positive or negative feedback (Forrester, 1961, 1968). For instance, the Limits to Growth model exhibits the classic pattern of 'S-shaped growth' shown in Figure 4, a dynamic perceivable in situations as diverse as the colonization by plants of a volcanic island or the saturation of the market for mobile telephones. According to the tenets of system dynamics, a system's behaviour is determined by the internal relationships or structure, rather than by events in the external environment, unless the system is pushed beyond the limits within which it can function.

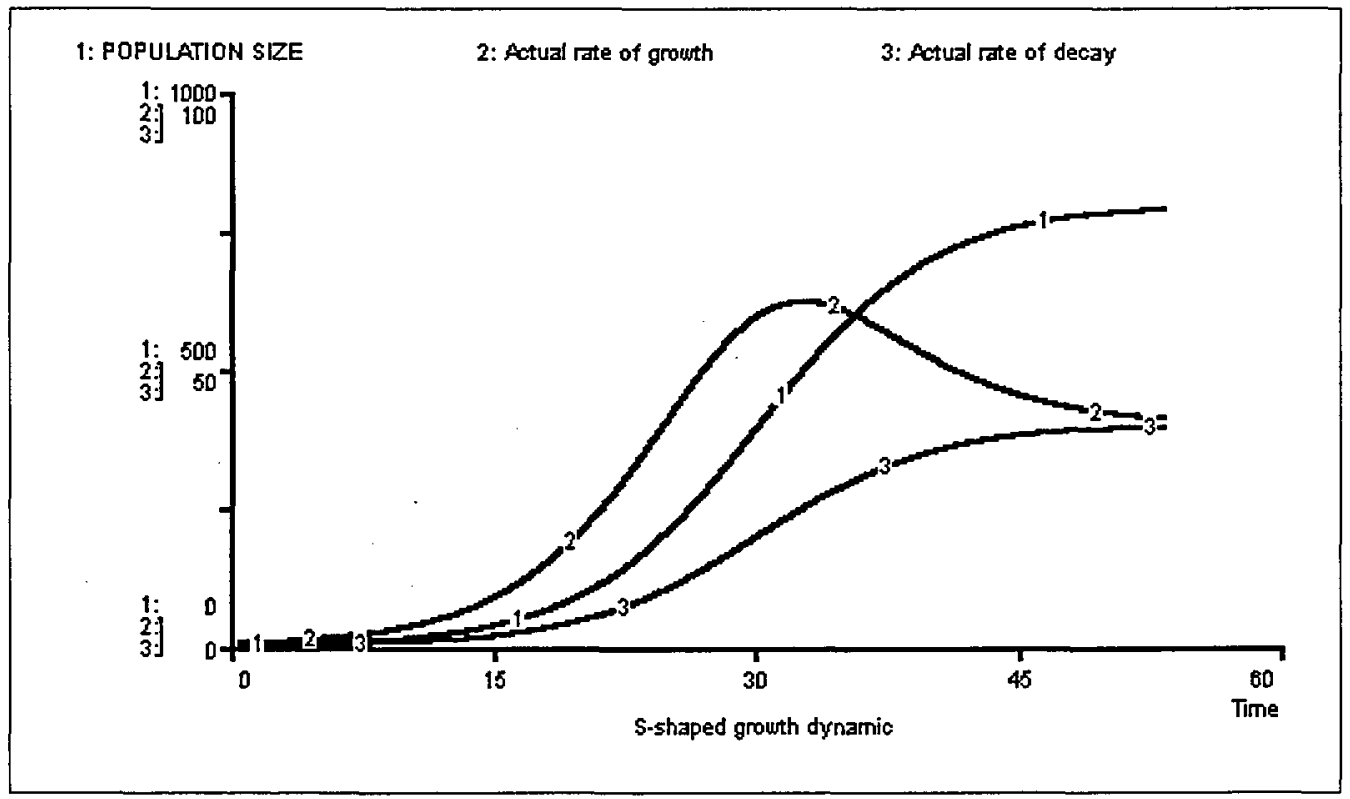

Figure 4: STELLA graph of the 'Limits to Growth' model

Figure 4 'tells the story' of S-shaped growth, an 'archetypal' pattern of behaviour in some systems (Senge, 1990). An initially low population (for instance, of plants or mobile telephones) possesses a slow rate of growth but this begins to increase as 'success breeds success' and the reinforcing effects of positive feedback dominate. The population grows most quickly when the difference between the actual rates of growth and decay (death or obsolescence) is at its greatest. From that point onwards, population growth is inhibited as a biophysical or socio-economic limit is approached and the counterbalancing effects of negative feedback become stronger. The population reaches a high and steady level once the growth and decay rates balance and, in effect, there is a saturation of the ecological or market niche at a level approaching the potential carrying capacity (of, say, majority ownership of mobile telephones).

\section{Constructing STELLA models}

STELLA models are assembled diagrammatically by arranging and connecting symbolic: pipes and taps (flows), tanks (stocks or accumulations), wires (carrying information about 
causal relationships) and converters (information or equation holders). This construction kit approach to model-building serves several purposes, it:

- encourages users to think about the circular, cause-and-effect relationships within the closed loops of a system dynamics model;

- automates the production of difference equations for the stocks;

- constrains the writing of equations for the flows and converters - these must include all the inputs shown in the diagram, and can include no other inputs.

Equations for the flows and converters are entered via an object's dialogue box and a complete set of equations can be inspected in the 'underlying' equation layer, as illustrated in the text box below.

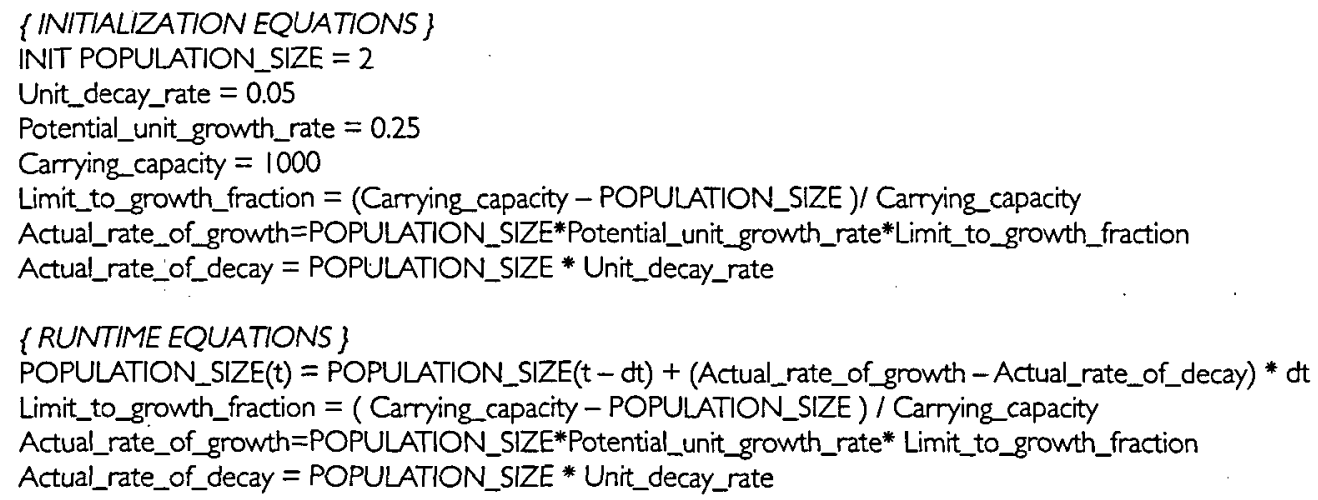

Notes: in the runtime stock equation: "POPULATION_SIZE $(t)=. . . "$

POPULATION_SIZE(t) is the value (in this case, between 2 and 1000 ) being calculated at time '(t)'.

POPULATION_SIZE(t-dt) was the value one time interval before, at time '(t-dt)'.

' $d t$ ' is the short time interval between successive iterations of the model.

Figure 5: The 'Limits to Growth' model: equations in order of execution

\section{Implications of STELLA}

To conclude this account of STELLA, David Squires and fellow colleagues were impressed by this modelling program because it:

- enabled students to see, modify and author models expressed in a formalism they could understand and that a computer could execute;

- could be used to prototype models for use in CAL games and simulations (Squires and Millwood, 1988), CIC developed, trialled and published around 130 games, simulations and CAL programs during the 1980 s - an average of one per month through the decade;

- had the potential to evolve into a simulation authoring system - suitable for teachers and lecturers with limited time, technical skills or financial resources. 


\section{From mainstream to backwater}

The 1980s were notable for the high levels of interest in modelling as a form of computerassisted learning, and for several pioneering initiatives in schools and colleges. Interest in the educational potential of modelling programs like STELLA was not restricted to CIC. There was a widespread interest in modelling amongst CAL developers and the wider educational community. For instance, classroom trials of STELLA led to the MODUS project (Hassell and Webb, 1990; Cox and Webb, 1994), and modelling featured in the IT component of the newly launched National Curriculum, whilst the London Mental Models Group obtained ESRC funding for research into the learning and teaching of modelling (Bliss et al., 1992; Mellar, Bliss, Boohan, Ogborn and Tompsett, 1994).

These high levels of interest were not sustained during the 1990 s and simulation modelling now seems to receive relatively little attention from learning technologists. This contrast with the 1980s is anomalous, given the:

- pedagogic potential of simulation modelling for student engagement and authorship;

- ease with which models and simulations can be assembled by students or teachers, using modelling programs like STELLA;

- comparative abundance of personal and institutionally owned computers;

- vastly improved capabilities of modern computers and networks.

The reasons for this anomalous situation are worthy of reflection and, perhaps, of empirical research. For instance, there may be more simulation modelling taking place than is apparent, with the classroom modelling activities of individual lecturers being relatively invisible to learning technologists. One might hypothesize that, in general, learning technologists focus upon national and institutional initiatives rather than lecturers' unreported activities within departments. This is something learning technologists could investigate within their own institutions and share with the wider community, either on an informal basis or as a more organized form of empirical research.

\section{Learning and teaching simulation modelling}

This section of the paper suggests ways forward and acknowledges some of the developments that have taken place over the past decade. If Laurillard suggests the simulation modelling 'glass' is not full, this section suggests it is partially full and filling slowly. Some approaches to simulation modelling are outlined, based on the growing pedagogic literature, and upon personal experience as a lecturer in physical geography at the former University of North London.

\section{Making it happen}

Students may first encounter specific models and the activity of modelling in their lectures, with practical work taking place in supervised 'laboratory' sessions where they gain handson experience of particular modelling programs. Students, often working in small groups, may begin with simple ready-made models and learn to explore and modify these before constructing their own models based on provided materials or information gathered from library research. Entirely free invention of models is less likely, although there is more scope for originality in students' projects and dissertations, especially at postgraduate level. 
Once students are familiar with the basic principles and practice in their subject field, lecturers can refer to models and modelling in other course modules, setting tasks to develop students' knowledge, skills and attitudes towards modelling. Participation in a range of modelling activities can extend students' experiences of models as tools to 'think with' and to 'think about' (Bliss, 1994a), and also of models as media for sharing ideas and explanations with others.

\section{Reasons for modelling}

Students may be unfamiliar with modelling as a professional or research practice and lecturers may need to describe the roles that modellers play in:

- prediction and control (for example, in engineering design);

- theory development (for example, in the biophysical and social sciences);

- policy-making and decision-support (for example, in business and government);

- education, training and entertainment (for example, in simulations and games).

Simulation modelling originated in the mathematical sciences and engineering as a means of predicting and controlling phenomena like the compression of gases, or the mechanical 'loading of structures. The extension of 'modelling to predict and control' from relatively well-theorized, predictable and universal domains, to the social and environmental sciences has been problematic (Bloomfield, 1986; Flood, 1999). Here, phenomena tend to be less well theorized and are likely to be less predictable, as with weather and economic forecasting (Ogborn and Mellar, 1994). The notions of 'modelling to develop theory' (Gilbert and Troitzsch, 1999), or 'modelling to learn' (De Geus, 1992) better suit business education and the context-sensitive, more 'situated' social sciences.

Social and economic models may also influence the phenomena they simulate, as people become aware of models and adjust their behaviour. On the one hand, this is a problem not faced by the modellers of biological, mechanical and electrical systems, where the principles of cybernetics and system dynamics were first formulated (Forrester, 1968; Lilienfeld, 1978). On the other hand, social responsiveness is turned to advantage where models are used to influence policy-makers and to inform public opinion. Environmentalists are amongst those who have 'modelled to persuade', for instance, the Club of Rome report on global environmental futures and its sequels (Meadows et al., 1972, 1992), and James Lovelock's imaginary Daisyworlds (Watson and Lovelock, 1983; Lovelock, 2000). The latter leads in short order to the notion of 'modelling to entertain' as exemplified by the SimEarth and SimCity type of computer games, which blur the boundaries between education and entertainment.

\section{Approaches to modelling}

Lecturers' reasons for including modelling in the curriculum will vary, depending on the subject field and course goals. This paper focuses on geographic and business education where social, economic, political and ethical issues are closely linked to the design and application of models in academic, personal, professional and public settings. It is desirable for students to understand what models are, how they are created and how they are used - whether to inform and persuade or to confuse and mislead. It is notable that we teach a large number of university students about the use and abuse of statistics but teach 
very few about the use and misuse of computer models - despite their widespread and significant applications.

A common reason for including modelling in the curriculum is that it reveals, and may improve, students' formal reasoning (Mandinach and Cline, 1994; Doerr, 1996; Sweeney and Sterman, 2000), with peer discussion and group-work playing supportive roles. The extent to which reasoning, communication or collaboration are prioritized is a matter for lecturers and course developers to determine along with other course goals. For instance, staff may choose to emphasize either:

- cognitive or communicative learning outcomes;

- individual or collaborative work;

- convergent tasks or open-ended problem-solving;

- the exploration of 'classic' models or the expression of students' models (Mellar and Bliss, 1994);

- general mathematical methods or program-specific techniques and 'work-arounds';

- idealized theories of modelling or case studies of modelling in practice.

Options like these, and others, are not mutually exclusive and the balance between them may vary over a period of several weeks or longer. For instance, students' modelling activities within a degree programme may culminate in assessed projects or in final dissertations where students assume more responsibility for their own aims and approaches.

\section{Introductory textbooks and resources}

Lecturers and students can pick and choose amongst numerous introductory textbooks, of which there is a range in fields like environmental modelling (Huggett, 1993; Kirkby, Naden Burt and Butcher, 1993; McGuffie and Henderson-Sellers, 1997). This range also includes program-specific textbooks with modelling activities based on EXCEL (Hardisty, Taylor and Metcalfe, 1993) and STELLA (Ford, 1999). In addition, there are more general texts that address the concerns of human geographers (Macmillan, 1989; Robinson, 1998), which place greater emphasis on critiques of models and of modelling itself.

Books and resources on systems modelling are appearing too, in business and management education (Coyle, 1996; Pidd, 1998; Senge, 1990; Senge, Kleiner, Roberts, Ross and Smith, 1994), and many of these include sections on, or are based upon, system dynamics. A recent and comprehensive textbook on 'Business Dynamics' (Sterman, 2000), is accompanied by a CD-ROM with models and three system dynamics programs: Vensim, ${ }^{2}$ Powersim ${ }^{3}$ and 'ithink' - the version of STELLA targeted at business markets (Repenning, 1998; Costanza and Voinov, 2001). Further tutorial materials and models are provided by SDEP - the System Dynamics in Education Project ${ }^{4}$ - on its MIT-hosted Website. The SDEP Road Maps ${ }^{5}$ contain some $11 \mathrm{MB}$ of introductory and more advanced tutorials, mostly in 'pdf' format, that are 'quality assured' by the MIT system dynamics group and can be reproduced for non-commercial purposes.

These recent books and electronic resources succeed earlier texts for the modelling language DYNAMO (Goodman, 1988; Roberts, Andersen, Deal, Garet and Shaffer, 1983) and tend to be less formal in approach and to assume less knowledge of mathematics. Peter 
Senge's books, in particular, emphasize the concepts of system dynamics and reasoning with paper-based, causal loop diagrams, rather than quantitative modelling on a computer. This approach directly addresses students' conceptual understanding whilst avoiding the complications that accompany quantification and the use of mathematics. These are issues that arise elsewhere, for instance, with younger students (Bliss, 1994b; Brosnan, 1994), and with the teaching of environmental systems (Inkpen, 1993).

Still, there are pitfalls with 'semi-quantitative' reasoning (Richardson, 1986 and 1997), and it is a moot point whether students should be introduced to causal loop-diagramming before STELLA or whether the full STELLA formalism should be introduced first, with diagramming as a subsequent simplification. Thus, a lecturer's choice of an introductory textbook or use of online materials may depend upon:

- the backgrounds and needs of the students;

- the curricular goals and reasons for teaching modelling;

- available modelling programs;

- the preferred formalism(s);

- their sequence of introduction.

Also, lecturers can choose between a number of modelling programs and are by no means restricted to those based on system dynamics. Gilbert and Troitzsch, for instance, suggest approaches based on the simulation of discrete events, cellular automata, intelligent agents or evolutionary processes may better appeal to social theoreticians.

To return to the example of STELLA, lecturers will find this has improved considerably over the last fifteen years or so and it now supports Windows computers. Also, it provides an additional communications or interface layer 'above' the original diagram and equation layers. This new layer supports several features, including:

- scene-setting introductions and tutorials with text, pictures and QuickTime movies;

- annotated step-by-step tours of a complete model or of selected parts to explain the underlying logic and behaviour;

- simulation 'control panels', such as the one shown in Figure 1, assembled from standard drag and drop components.

In effect, STELLA has become the type of simulation authoring environment originally anticipated by David Squires. It is an environment in which lecturers can rapidly produce models and simulations, without the need for conventional programming skills or the associated development resources and timescales.

\section{Reflections}

There have therefore been several developments during the 1990s: the publication of introductory textbooks and online resources, and a growth in the number and quality of modelling programs. Whilst Laurillard may be correct in asserting the productive media are underutilized in higher education, the above are grounds for some optimism, at least with respect to systems modelling in geographic and business education. Lecturers and learning technologists working in these fields can build upon broader and more substantial foundations than those available one or two decades ago. 


\section{Educational development roles for learning technologists}

This final part of the paper suggests learning technologists may be well placed to raise awareness of simulation modelling in higher education. Many academic staff are appointed on the grounds of their research and income-generating potential rather than their pedagogic repertoires or use of learning technologies. Although most lecturers new to higher education receive some training, they rarely experience anything equivalent to their lengthy apprenticeships as researchers. Many rely on interested colleagues and support staff to suggest improvements to their course modules or to recommend 'new' approaches to learning and teaching.

Learning technologists, through their contacts with lecturers and course development teams, are well positioned to:

- suggest simulation modelling as a learning activity - when it otherwise may be overlooked;

- draw attention to available modelling programs, online resources and introductory textbooks either in staff's own fields or in related ones;

- assist in the design and production of multimedia support materials and tutorials for:

- simulations in programs like STELLA;

- resource-based learning materials on simulation modelling;

- advise on the design, assessment and evaluation of modelling activities - as instances of the use of learning technologies;

- contribute to the development of new learning environments supporting collaborative modelling activities.

Individual learning technologists may not be able to perform all of these roles but one hopes they will contribute to curriculum development both in terms of their technical and educational expertise. Learning technologists benefit from meeting teaching staff from around an institution and can point to practice in different departments. They can help interested academics to network and to share their experiences of approaches outside the traditional repertoire of lectures, seminars, practicals and tutorials.

Once academic staff are familiar with programs like STELLA, and simulation modelling as a student activity, they may be self-sufficient or need support only to produce multimedia-rich introductions and tutorials. Many academic staff are unused to developing student materials for resource-based or distance learning, whilst this is a more familiar activity to learning technologists. Similarly, academics can benefit from introductions to the literature on the evaluation of learning technologies and the assessment of computer-assisted learning activities.

Finally, Laurillard notes the potential for combining microworlds and modelling programs with communications technologies and points to developments in the commercial and entertainment sectors. This is the type of innovation that would have interested David Squires and one looks for learning technologists to follow his example and develop new categories of educational applications. This will be neither cheap nor easy but it is a field in which learning technologists could make important contributions. 


\section{Conclusions}

This paper has drawn attention to simulation modelling and has sought to raise awareness amongst learning technologists of this distinctive, if relatively neglected, pedagogic activity. Simulation modelling is advocated on the grounds that it:

- makes cost-effective use of lecturers' and students' time. Educational simulations, models or model fragments can be quickly retrieved, modified or created with software such as STELLA;

- enables students to learn through modifying and creating simulation models within their theoretical field - activities that only the productive media support;

- introduces students to modelling as a significant academic and professional practice;

- fosters cognitive, communicative and collaborative student activities;

- facilitates a participative and productive approach to learning, one that realizes the creative-transformative potential of learning technologies.

Whilst Laurillard may have exaggerated the underdevelopment and underutilization of simulation modelling, there clearly are opportunities for learning technologists to promote and support its 'rediscovery'. Contributions may take many forms, including making suggestions to lecturers, assisting with the production of learning materials, and contributing to software development projects. Simulation modelling provides many challenges for learning technologists, of the type that David Squires used to seize with relish. Now new champions are required, people who can once more bring simulation modelling into the mainstream of higher education and help develop curricula fit for the twenty-first century.

\section{Notes and relevant Websites}

The following URLs were last accessed in August 2002.

'STELLA ${ }^{\circledR}$ and 'ithink ${ }^{\circledR}$ ' are produced by High Performance Systems: http://www.hpsinc.com and distributed in the UK by Cognitus, http://www.cognitus.co.uk/

${ }^{2}$ Vensim ${ }^{\circledR}$ is produced by Ventana Systems. Vensim PLE is free for educational use and downloadable from: http://www. vensim.com/

${ }^{3}$ Powersim ${ }^{0}$ is produced by the Powersim Corporation: http://www.powersim.com/

${ }^{4}$ System Dynamics Education Project (SDEP): http://sysdyn.mit.edu/home.asp

${ }^{5}$ SDEP Road Maps (for STELLA and Vensim PLE): http://sysdyn.mit.edulroadmaps/home.html

Lists of online resources for systems dynamics and systems thinking:

Creative Learning Exchange, additional resource links: http://www.clexchange.org/links/

Desert Island Dynamics - An Annotated Survey of the Essential System Dynamics Literature: http://web.mit.edu/jsterman/www/DID.html

Günther Ossimitz: System Dynamics/Systems Thinking Mega Link List: http://www.uni-klu.ac.at/users/gossimit/links/bookmksd.htm 
System Dynamics - Distance Learning: http://www.albany.edu/cpr/sds/distant_learning.htm

\section{References}

Bliss, J., Ogborn, J., Boohan, R., Briggs, J., Brosnan, T., Brough, D., Mellar, H., Miller, R., Nash, C., Rodgers, C. and Sakonidis, B. (1992), 'Reasoning supported by computational tools', Computers and Education, 18 (1), 1-9.

Bliss, J. (1994a), 'From mental models to modelling', in Mellar et al., Learning with Artificial Worlds: Computer Based Modelling in the Curriculum.

Bliss, J. (1994b), 'Causality and common sense reasoning', in Mellar et al., Learning with Artificial Worlds: Computer Based Modelling in the Curriculum.

Bloomfield, B. P. (1986), Modelling the World: The Social Constructions of Systems Analysts, Oxford: Basil Blackwell.

Brosnan, T. (1994), 'Using spreadsheets to develop understanding in science', in Mellar et al., Learning with Artificial Worlds: Computer Based Modelling in the Curriculum.

Costanza, R. and Voinov, A. (2001), 'Modeling ecological and economic systems with STELLA: Part III', Ecological Modelling, 143 (1), 1-7.

Cox, M. and Webb, M. (1994), 'Developing software and curriculum materials: the MODUS Project', in Mellar et al,, Learning with Artificial Worlds: Computer Based Modelling in the Curriculum.

Coyle, R. G. (1996), System Dynamics Modelling: A Practical Approach, London: Chapman and Hall.

De Geus, A. P. (1992), 'Modelling to predict or to learn?', European Journal of Operational Research, 59 (1), 1-5.

Doerr, H. M. (1996), 'STELLA ten years later: a review of the literature', International Journal of Computers for Mathematics Learning, 1 (2), 201-24.

Flood, R. L. (1999), Rethinking the Fifth Discipline: Learning within the Unknowable, London: Routledge.

Ford, A. (1999), Modeling the Environment: An Introduction to System Dynamics Modeling of Environmental Systems, Washington DC: Island Press.

Forrester, J. W. (1961), Industrial Dynamics, Cambridge, MA: Wright-Allen Press.

Forrester, J. W. (1968), Principles of Systems, 2nd edn, Cambridge, MA: Wright-Allen Press.

Gilbert, N. and Troitzsch, K. G. (1999), Simulation for the Social Scientist, Buckingham: Open University Press.

Goodman, M. R. (1988), Study Notes in System Dynamics, Cambridge, MA: The MIT Press (republication of 1974 original, Wright-Allen Press).

Hardisty, J., Taylor, D. M. and Metcalfe, S. E. (1993), Computerised Environmental Modelling: A Practical Introduction Using Excel, Chichester: John Wiley \& Sons. 
Hartley, R. J. (1984), 'Evaluation of a CAL package for modelling', Computers and Education, 8 (1), 69-76.

Hartley, R. J. and Lewis, R. (1984), 'A computer language system for model-building and experimentation', International Journal of Mathematical Education in Science and Technology, 13 (4), 391-400.

Hassell, D. J. and Webb, M. E. (1990), 'MODUS: the integrated modelling system', Computers and Education, 15 (3), 265-70.

Huggett, R. J. (1993), Modelling the Human Impact on Nature: Systems Analysis of Environmental Problems, Oxford: Oxford University Press.

Inkpen, R. (1993), 'A low-tech approach to teaching physical systems', Journal of Geography in Higher Education, 17 (1), 37-46.

Kirkby, M. J., Naden, P. S., Burt, T. P. and Butcher, D. P. (1993), Computer Simulation in Physical Geography, Chichester: John Wiley \& Sons.

Lal, S. (1987), 'Two cheers for DMS', Journal of Computer Assisted Learning, 3 (3), 176-80.

Laurillard, D. (2002), Rethinking University Teaching: A Conversational Framework for the Effective Use of Learning Technologies, 2nd edn, London: Routledge.

Lilienfeld, R. (1978), The Rise of Systems Theory: An Ideological Analysis, New York: John Wiley \& Sons.

Lovelock, J. E. (2000), Homage to Gaia: The Life of an Independent Scientist, Oxford: Oxford University Press.

McGuffie, K. and Henderson-Sellers, A. (1997), A Climate Modelling Primer, 2nd edn, Chichester: John Wiley \& Sons.

Macmillan, B. (ed.) (1989), Remodelling Geography, Oxford: Basil Blackwell.

Mandinach, E. B. and Cline, H. F. (1994), Classroom Dynamics: Implementing a Technology-Based Learning Environment, Hillsdale NJ: Lawrence Erlbaum Associates.

Meadows, D. H., Meadows, D. L., Jørgen, R. and Behrens, W. W. III (1972), The Limits to Growth: A Report for the CLUB OF ROME'S Project on the Predicament of Mankind, New York: Universe Books.

Meadows, D. H., Meadows, D. L. and Jørgen, R. (1992), Beyond the Limits: Global Collapse or a Sustainable Future, London: Earthscan.

Mellar, H., Bliss, J., Boohan, R., Ogborn, J. and Tompsett, C. (eds.) (1994), Learning with Artificial Worlds: Computer Based Modelling in the Curriculum, London: Falmer Press.

Mellar, H. and Bliss, J. (1994), 'Introduction: modelling and education', in Mellar et al., Learning with Artificial Worlds: Computer Based Modelling in the Curriculum.

Ogborn, J. and Mellar H. (1994), 'Models: their makers, uses and problems', in Mellar et al., Learning with Artificial Worlds: Computer Based Modelling in the Curriculum. 
Pidd, M. (1998), Computer Simulation in Management Science, Chichester: John Wiley \& Sons.

Repenning, N. (1998), Formulating Models of Simple Systems using Vensim PLE, available from: http://sysdyn.mit.edu/sdep/Roadmaps/RM2/D-4697-2.pdf (last accessed August 2002).

Richardson, G. P. (1986), 'Problems with causal-loop diagrams', System Dynamics Review, $2(2), 158-70$.

Richardson, G. P. (1997), 'Problems in causal-loop diagrams revisited', System Dynamics Review, 13 (3), 247-52.

Riley, D. (1986), 'A case for classroom research into models, modelling and CAL in secondary geography', in W. A. Kent and R. Lewis, Computer Assisted Learning in the Humanities and Social Sciences, Oxford: Blackwell Scientific Publications.

Roberts, N., Andersen, D., Deal, R., Garet, M. and Shaffer, W. (1983), Introduction to Computer Simulation: A System Dynamics Modeling Approach, Reading, MA: AddisonWesley.

Robinson, G. M. (1998), Methods and Techniques in Human Geography, Chichester: John Wiley \& Sons.

Seale, J. and Rius-Riu, M. (eds.) (2001), An Introduction to Learning Technology within Tertiary Education in the UK, Oxford: Association for Learning Technology.

Senge, P. M. (1990), The Fifth Discipline: The Art and Practice of the Learning Organization, London: Random House.

Senge, P. M., Kleiner, A., Roberts, C., Ross, R. B. and Smith, B. J. (1994), The Fifth Discipline Fieldbook: Strategies and Tools for Building a Learning Organization, London: Nicholas Brealey Publishing.

Squires, D. J. and Millwood, R. (1988), 'The influence of new software environments on CAL development', Computers and Education, 12 (1), 67-71.

Squires, D. J. and McDougall, A. (1986), 'Computer-based microworlds - a definition to aid design', Computers and Education, 10 (3), 375-8.

Sterman, J. D. (2000), Business Dynamics: Systems Thinking and Modelling for a Complex World, Boston, MA: Irwin McGraw-Hill.

Sweeney, L. B. and Sterman, J. D. (2000), 'Bathtub dynamics: initial results of a systems thinking inventory', System Dynamics Review, 16 (4), 249-86.

Watson, A. J. and Lovelock, J. E. (1983), 'Biological homeostasis of the global environment: the parable of Daisyworld', Tellus, 95 (B), 284-9.

Watson, D. (1987), Developing CAL: Computers in the Curriculum, London: Harper \& Row.

Wong, D. (1987), 'Teaching A-level physics through microcomputer dynamic modelling: I. teaching methods', Journal of Computer Assisted Learning, 3 (2), 105-16. 